\title{
PTPN14 is required for the density-dependent control of YAP1
}

\author{
Wenqi Wang, ${ }^{1}$ Jun Huang, ${ }^{2}$ Xin Wang, ${ }^{1}$ Jingsong Yuan, ${ }^{1}$ Xu Li, ${ }^{1}$ Lin Feng, ${ }^{1}$ Jae-Il Park, ${ }^{1}$ and Junjie Chen ${ }^{1,3}$ \\ ${ }^{1}$ Department of Experimental Radiation Oncology, The University of Texas M.D. Anderson Cancer Center, Houston, Texas \\ 77030, USA; ${ }^{2}$ Life Sciences Institute, Zhejiang University, Hangzhou, Zhejiang 310058, China
}

\begin{abstract}
Through an shRNA-mediated loss-of-function screen, we identified PTPN14 as a potential tumor suppressor. PTPN14 interacts with yes-associated protein 1 (YAP1), a member of the hippo signaling pathway. We showed that PTPN14 promotes the nucleus-to-cytoplasm translocation of YAP1 during contact inhibition and thus inhibits YAP1 transactivation activity. Interestingly, PTPN14 protein stability was positively controlled by cell density. We identified the CRL2 ${ }^{\mathrm{LRR} 1}$ (cullin2 RING ubiquitin ligase complex/leucine-rich repeat protein 1) complex as the E3 ligase that targets PTPN14 for degradation at low cell density. Collectively, these data suggest that PTPN14 acts to suppress cell proliferation by promoting cell density-dependent cytoplasmic translocation of YAP1.
\end{abstract}

[Keywords: tumor suppressor; PTPN14; YAP1; hippo pathway; cell density; CRL2 ${ }^{\text {LRR1 }}$ ]

Supplemental material is available for this article.

Received March 27, 2012; revised version accepted July 17, 2012.

Inactivation of tumor suppressors and activation of oncogenes lead to uncontrolled proliferation and neoplastic transformation (Hanahan and Weinberg 2011). In recent years, as the remarkable prevalence of activated protein tyrosine kinases (TKs) as oncoproteins and their mutations are being identified in numerous cancers, the control of protein tyrosine phosphorylation has been considered to play a central role in ensuring the homeostasis of cellular physiology and thus preventing tumorigenesis (Lemmon and Schlessinger 2010). Another family of enzymes, protein tyrosine phosphatases (PTPs), can contribute to this equilibrium of protein tyrosine phosphorylation and thereby antagonize the oncogenic activities of TKs (Alonso et al. 2004; Tonks 2006). Therefore, PTPs are prominently considered to act as tumor suppressors. Indeed, numerous genetic alterations have been identified in genes encoding PTPs, which contribute to their functional loss and, consequently, cancer development (Tonks 2006; Julien et al. 2011). For example, the receptor tyrosine phosphatases PTPRA (Ardini et al. 2000) and PTPRG (Zheng et al. 2000) were found to be down-regulated in breast cancers. PTEN (Liaw et al. 1997; Garcia et al. 2004) and PTPRF (Levea et al. 2000) were shown to harbor genetic deletion or mutations in several tumor types. PTPN12 was recently discovered to be frequently inactivated in triple-negative breast cancers (Sun et al. 2011). PTPN13 is considered a suppressor for HER2positive breast cancers, as it can antagonize HER2

${ }^{3}$ Corresponding author

E-mail jchen8@mdanderson.org

Article is online at http://www.genesdev.org/cgi/doi/10.1101/gad.192955.112. activation (Zhu et al. 2008). PTPRK (Nakamura et al. 2003), PTPN7 (Fridberg et al. 2008), and PTPN13 (Ying et al. 2006) were found to be down-regulated or mutated in lymphoma. Loss of function of DUSP1 (Denkert et al. 2002) and DUPS6 (Chan et al. 2008) was detected in ovarian cancers. Although the enzyme properties and crystal structures of many PTPs have been studied extensively (Wadham et al. 2003; Julien et al. 2011), the detailed mechanisms of their tumor suppressor functions remain to be explored because of the slow progress in the identification of their physiological substrates. Remarkably, some PTPs regulate cellular processes in a manner that is independent of their phosphatase activities. For example, PTPRM can stabilize cell-cell adhesion and protect tissue homeostasis through its physical interaction with E-cadherin (Sallee et al. 2006) and protein kinase C (Hellberg et al. 2002). These findings suggest that different PTPs may use distinct mechanisms in regulating various cellular signaling events.

To identify tumor suppressors involved in breast cancer development, we performed a loss-of-function screen of human PTPs and identified PTPN14 as a potential tumor suppressor. PTPN14 (also known as PTPD2) is a nonreceptor PTP whose cellular functions are not well characterized. PTPN14 was initially identified as a cytoskeleton-associated protein with an N-terminal FERM domain (Smith et al. 1995), which plays important roles in cell adhesion and proliferation (Ogata et al. 1999). In HUVEC cells, PTPN14 was shown to mediate $\beta$-catenin dephosphorylation at adhesion junctions (Wadham et al. 2003). Moreover, density-dependent nucleus-to-cytoplasm translocation of PTPN14 was reported to be important for 
cell proliferation (Wadham et al. 2000), and overexpression of PTPN14 in MDCK cells led to the epithelialmesenchymal transition (Wyatt et al. 2007; Wyatt and Khew-Goodall 2008). Interestingly, several PTPN14 mutations have been shown to be associated with human breast and colorectal cancers, implying that PTPN14 may act as a tumor suppressor (Wang et al. 2004; Laczmanska and Sasiadek 2011). Loss-of-function mutation of PTPN14 was also found to be correlated with autosomal recessive lymphedema-choanal atresia syndrome (Au et al. 2010). More recently, PTPN14 was shown to regulate angiogenesis and be involved in a vascular dysplasia syndrome, hereditary hemorrhagic telangiectasia (Benzinou et al. 2012). However, the mechanisms by which PTPN14 acts in these disease processes remain unknown.

In this study, we show that PTPN14 associates with and negatively regulates yes-associated protein 1 (YAP1) (Yagi et al. 1999), the key oncoprotein that acts downstream from the hippo pathway. PTPN14 protein level was elevated in cells at high density, which correlated with cytoplasmic location and inhibition of YAP1. The stability of PTPN14 was controlled by cell density via the CRL2 ${ }^{\text {LRR1 }}$ (cullin2 RING ubiquitin ligase complex/leucine-rich repeat protein 1) E3 ligase complex. Together our findings suggest that PTPN14 acts as a negative regulator for YAP1 in a cell density-dependent manner.

\section{Results}

Loss of PTPN14 transforms MCF10A cells

and disrupts normal acini formation

in three-dimensional (3D) culture

To identify putative tumor suppressors involved in breast cancer development, we performed an shRNA-based lossof-function screen of the PTP family in two normal immortalized mammary epithelial cell lines: MCF10A and HMLE. Following shRNA knockdown, cells were subjected to anchorage-independent growth in soft agar. Candidates that scored high for colony formation in both cell lines were selected for further analysis. We used MCF10A acini formation as an independent assay for tumorigenesis. In normal mammary glands, strict control of cell proliferation, apoptosis, and polarity is required for construction of the mammary epithelium. MCF10A cells can form polarized acinar structures in 3D culture, which mimic mammary acini formation in vivo (Debnath et al. 2003). The disruption of normal acini formation leads to neoplastic transformation (Bissell et al. 2002; Debnath et al. 2003) and can be used as an in vitro assay for oncogenic potential. PTPN14 was the top candidate in all of these loss-of-function screens.

To verify that it is PTPN14 knockdown that contributes to these phenotypes, five shRNAs were used individually to knock down PTPN14 in MCF10A cells. Two of the five PTPN14 shRNAs induced robust anchorageindependent growth of MCF10A cells, and the degree of anchorage-independent growth correlated with the knockdown efficiency of individual PTPN14 shRNAs (Fig. 1A,B). Similarly, the normal acinar structure was disrupted in

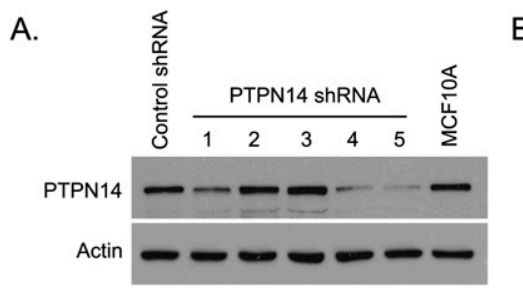

B.

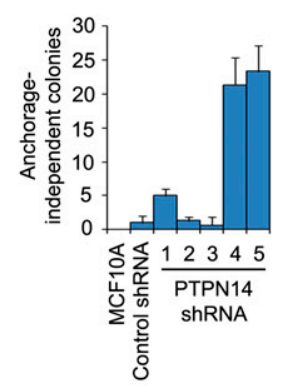

C.

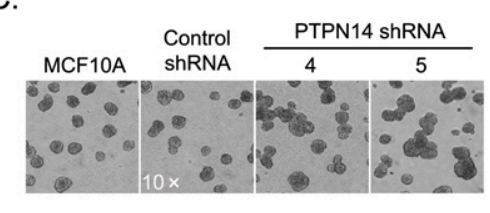

D.

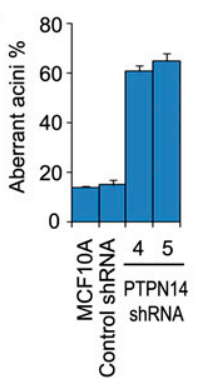

Figure 1. PTPN14 suppresses transformation of MCF10A cells. (A) PTPN14 was down-regulated in MCF10A cells infected by viruses encoding PTPN14-specific shRNAs. PTPN14 expression in the indicated shRNA transduced MCF10A cells was detected by immunoblotting using a PTPN14 antibody. (B) PTPN14 depletion led to transformation of MCF10A cells. Anchorageindependent growth for indicated PTPN14 shRNA transduced MCF10A cells is shown. Data are presented as mean \pm SD from three different experiments. $(C)$ Normal acinar morphogenesis was disrupted in PTPN14-depleted cells. The analysis of acini formation in 3D cultures was performed in MCF10A cells expressing the indicated shRNAs. $(D)$ Aberrant acini of indicated PTPN14 shRNA-expressing MCF10A cells in $C$ were quantified. Data are presented as mean \pm SD from three different experiments.

PTPN14 knockdown cells but not in MCF10A cells transduced with control shRNA (Fig. 1C,D). The percentage of aberrant acini exceeded 60\% in PTPN14 knockdown cells, whereas it was $\sim 15 \%$ in control cells. These aberrant acini displayed increased cell proliferation (Supplemental Fig. $\mathrm{S} 1 \mathrm{~A}, \mathrm{~B})$ and the development of large multiacinar structures (Fig. 1C). Together, these observations indicate that PTPN14 plays a critical role in regulating cell proliferation during acini formation.

\section{PTPN14 interacts with YAP1}

To determine the mechanism by which PTPN14 suppresses cellular transformation, we isolated the PTPN14containing protein complex from 293T cells using tandem affinity purification and subjected it to mass spectrometry analysis (Fig. 2A). One of the major PTPN14associated proteins is YAP1 (Yagi et al. 1999). Interestingly, PTPN14 was also identified as one of the major YAP1-binding proteins in both 293T and MCF10A cells (Wang et al. 2011). These data suggest that YAP1 is a potential binding partner of PTPN14. Endogenous 
A.

\begin{tabular}{lc} 
Protein & Peptides No. \\
\hline PTPN14 & $\underline{93}$ \\
AMOT & 39 \\
YWHAE & 25 \\
CUL2 & 14 \\
YAP1 & 11 \\
PLK1 & 11 \\
DDB1 & 11 \\
PPP2R1A & 9 \\
PPP2R2A & 7 \\
WWC1 & 7 \\
YWHAZ & 6 \\
YWHAB & 6 \\
WWC2 & 6 \\
UBC & 4 \\
COPS4 & 4 \\
STK3 & 3 \\
PPIL5 & 2 \\
WWP1 & 2 \\
WWP2 & 1 \\
CSNK1D & 1
\end{tabular}

B.

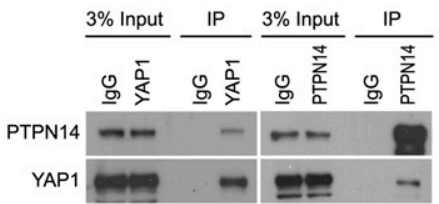

E.

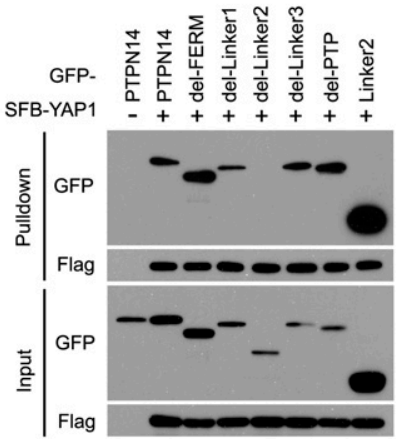

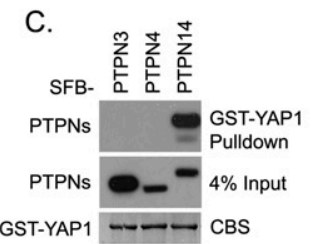

GST-YAP1 -
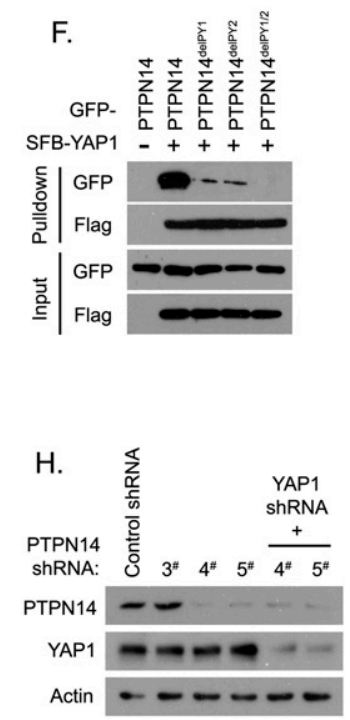
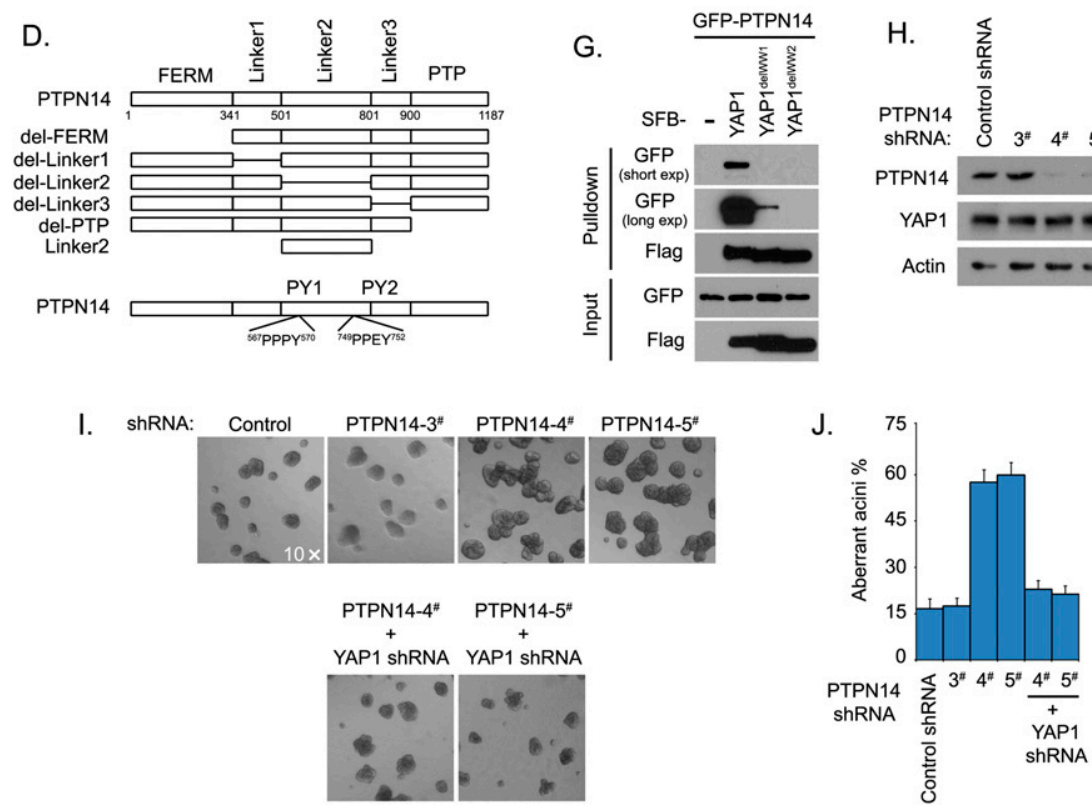

Figure 2. YAP1 associates with PTPN14 and acts downstream from PTPN14 in MCF10A transformation. (A) YAP1 was identified as a PTPN14-associated protein. PTPN14 was used as the bait (underlined) for tandem affinity purification and mass spectrometry analysis. The proteins identified in the PTPN14-containing complexes are listed together with the number of peptides for each protein identified by mass spectrometry. $(B)$ Association of endogenous PTPN14 and YAP1 was confirmed by coimmunoprecipitation experiments. An endogenous immunoprecipitation (IP) assay was performed using 293T cell exacts and anti-YAP1/ PTPN14 antibody. Rabbit normal IgG was used as control. Immunoblotting was performed with the indicated anti-PTPN14 anti-serum or anti-YAP1 antibody. (C) PTPN14 binds directly to YAP1. Bacterially expressed and purified GST-YAP1 fusion protein was used to pull down exogenously expressed SFB-tagged PTPN3, PTPN4, and PTPN14 in vitro. (CBS) Coomassie blue stain. (D) The schematic illustration shows the truncations and deletion mutants of PTPN14 used in this study. (E) The second linker domain of PTPN14 was required for its association with YAP1. 293T cells were transfected with constructs encoding the indicated wild-type and PTPN14 truncations and deletion mutants together with a construct encoding SFB-YAP1. Pull-down experiments were carried out using S-protein beads, and immunoblotting was performed with the indicated antibodies recognizing GFP or Flag tag. $(F)$ Two PY motifs located within the second linker domain of PTPN14 were required for its interaction with YAP1. 293T cells were transfected with constructs encoding wild-type or the indicated PTPN14 PY motif deletion mutants together with a construct encoding SFB-YAP1. Pull-down experiments were carried out using S-protein beads, and immunoblotting was performed with the indicated antibodies recognizing GFP or Flag tag. (G) Two WW domains of YAP1 were required for its interaction with PTPN14. 293T cells were transfected with constructs encoding GFPtagged PTPN14 together with constructs encoding SFB-tagged wild-type or the indicated WW domain deletion mutants of YAP1. Pulldown experiments were carried out using S-protein beads, and immunoblotting was performed with the indicated antibodies recognizing GFP or Flag tag. Both short time exposure (short exp) and long time exposure (long exp) of anti-GFP immunoblotting were included. $(H)$ Knockdown YAP1 was achieved in PTPN14-depleted MCF10A cells. MCF10A cells transduced with the indicated shRNAs were collected and immunoblotted with, respectively, antibodies recognizing PTPN14, YAP1, and actin. $(I)$ Knockdown of YAP1 can restore the normal acini morphogenesis in PTPN14-depleted MCF10A cells. Acini formation in 3D culture was analyzed in MCF10A cells expressing the indicated shRNAs. (J) Aberrant acini in the indicated shRNA-expressing MCF10A cells shown in $I$ were quantified. Data are presented as mean \pm SD from three different experiments. 
coimmunoprecipitation experiments confirmed their interaction (Fig. 2B). Moreover, bacterially purified GSTYAP1 specifically pulled down exogenously expressed $S$ protein-Flag epitope-SBP protein (SFB)-labeled PTPN14 but not PTPN3 or PTPN4, two other nonreceptor members of the PTP family (Fig. 2C), indicating that PTPN14 specifically interacts with YAP1.

\section{PY motifs of PTPN14 and WW domains of YAP1 bridge the interaction between these two proteins}

To identify the YAP-binding domain on PTPN14, several PTPN14 truncation and internal deletion mutants were generated (Fig. 2D). As shown in Figure 2E, only the deletion of the second linker region disrupted the interaction between PTPN14 and YAP1, suggesting that the second linker region of PTPN14 is required for its binding to YAP1. A majority of YAP1-interacting proteins associate with YAP1 through the binding of their PY motif (PPXY) with the YAP1 WW domains (Sudol et al. 1995; Webb et al. 2011). Analysis of PTPN14 amino acid sequence revealed two PY motifs in the second linker region (Fig. 2D). We generated deletion mutants of PTPN14, which lack the first PY motif (delPY1), the second PY motif (delPY2), or both PY motifs (delPY1/2). As shown in Figure 2F, both single PY motif mutants dramatically reduced their association with YAP1, and the double PY motif mutant totally disrupted its ability to bind to YAP1. Consistently, we found that both YAP1 WW domains contributed to its binding to PTPN14, with the second WW domain being more important for this interaction (Fig. 2G). These data suggest that the interaction between these two proteins is mediated by the two PY motifs located in the second linker region of PTPN14 and the two WW domains of YAP1.

\section{YAP1 is the downstream target of PTPN14 during MCF10A acini formation}

Since the oncogene YAP1 was identified as the major binding partner of PTPN14, we wondered whether YAP1 would contribute to aberrant acini formation in PTPN14 knockdown cells. To test this possibility, we used shRNA to down-regulate YAP1 in two groups of PTPN14-depleted MCF10A cells (Fig. 2H). These double-knockdown MCF10A cells were subjected to acini formation assay in $3 \mathrm{D}$ culture, with the PTPN14-depleted cells as controls. As shown in Figure 2I, knockdown of YAP1 reversed the aberrant acini formation. We observed almost normal size of acini formed by these double-knockdown cells, accompanied by a normal level of cell proliferation (Supplemental Fig. S1A,B). The percentage of aberrant acini in the PTPN14 and YAP1 double-knockdown cells was at a level $(\sim 17 \%)$ similar to that of MCF10A cells, while the PTPN14 single-knockdown cells showed a higher level of aberrant acini formation $(\sim 60 \%)$ (Fig. 2J). These data indicate that inhibition of YAP1 oncogenic function is probably one of the mechanisms by which PTPN14 negatively regulates cell proliferation.
PTPN14 can translocate YAP1 from the nucleus to the cytoplasm

YAP1 is the key component of the hippo signaling pathway, which has been identified as a critical pathway involved in density-dependent contact inhibition and organ size control in recent years (Huang et al. 2005; Camargo et al. 2007; Pan 2007; Zhao et al. 2007, 2008a; Zeng and Hong 2008). Indeed, YAP1 subcellular localization can be controlled by cell density (Zhao et al. 2007). In sparsely growing cells, YAP1 predominantly localizes in the nucleus, where it acts as a transcriptional coactivator for some proliferation- and/or anti-apoptosisrelated genes, including CTGF (Zhao et al. 2008b), AREG (Zhang et al. 2009), BIRC5 (Da et al. 2009), and cIAP1 (Zender et al. 2006). In confluent cells where contact inhibition occurs, YAP1 mostly accumulates in the cytoplasm and therefore loses its transcriptional coactivation activity.

Exactly how YAP1 localization is regulated under various conditions remains to be further defined. It was proposed that when cells reach confluence, cell-cell interaction and cytoskeleton rearrangement trigger a cascade of cell signaling to activate the hippo pathway. Two components in this pathway, MST1/2 and LATS1/2, get activated and coordinate to phosphorylate YAP1 at the Ser127 site. The 14-3-3 protein recognizes the phosphorylated YAP1 and sequesters it in the cytoplasm, which is the suggested mechanism for regulating YAP1 by cell density via the hippo pathway (Zhao et al. 2007). In recent years, several groups, including us, have reported that angiomotin family proteins AMOT, AMOTL1, and AMOTL2 can retain YAP1 in cytosol through a direct protein-protein interaction that occurs independently of YAP1 phosphorylation (Chan et al. 2011; Wang et al. 2011; Zhao et al. 2011; Oka et al. 2012). Since the association between PTPN14 and YAP1 is similar to that between angiomotin protein family members and YAP1, we asked whether PTPN14 could also translocate YAP1 from the nucleus to the cytoplasm.

Exogenously expressed PTPN14 mostly localized in the cytoplasm and partially colocalized with actin filaments at the plasma membrane (Fig. 3A). Endogenous YAP1 showed mostly nuclear staining with mild cytoplasm localization in the sparse cells (i.e., low density) (Fig. 3A). However, when PTPN14 was overexpressed, we observed a dramatic translocation of YAP1 from the nucleus to the cytoplasm (Fig. 3B). This translocation was independent of PTPN14 phosphatase activity, as the phosphatase catalytic-dead PTPN14 mutant (PTPN14 ${ }^{\mathrm{C} 1121 \mathrm{~S}}$ ) (Barr et al. 2006) could still translocate YAP1 to the cytoplasm (Fig. 3B). However, the two PY motif deletion mutant of PTPN14 $\left(\mathrm{PTPN} 14^{\text {delPY} 1 / 2}\right)$, which disrupts the association of PTPN14 with YAP1 (Fig. 2F), failed to translocate YAP1 to the cytoplasm (Fig. 3B). Collectively, these findings suggest that PTPN14 can mediate the translocation of YAP1 from the nucleus to the cytoplasm via their physical interaction and thereby inhibit YAP1 transcriptional functions. 
A.

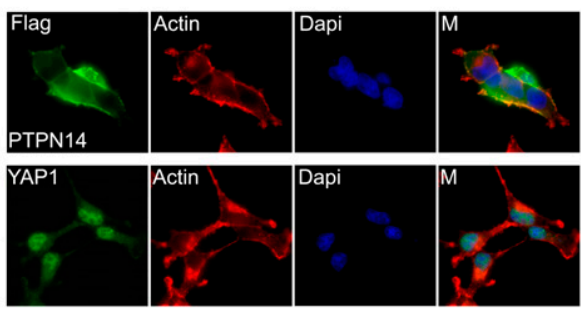

B.

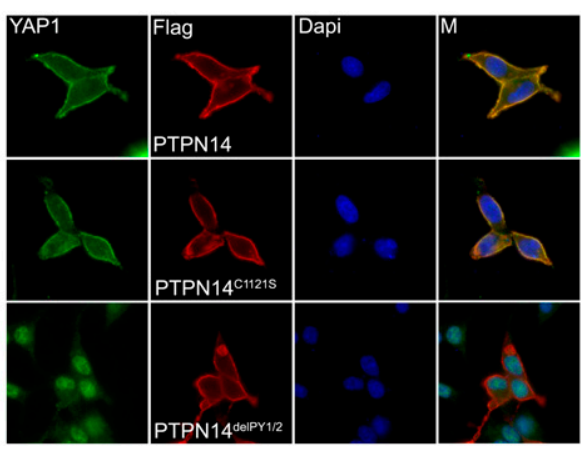

Figure 3. PTPN14 induces translocation of YAP1 from the nucleus to the cytoplasm. (A) Cellular localization of PTPN14 and YAP1 in HEK293 cells. Cells were transfected with constructs encoding SFB-tagged PTPN14. The cellular localization of PTPN14 was detected by anti-Flag immunostaining. The localization of endogenous YAP1 was detected by immunostaining using anti-YAP1 antibody. Actin filaments were labeled with TRITC-conjugated phalloidin. Nuclei were stained by DAPI. (M) Merged. (B) PY motifs of PTPN14 were required for YAP1 translocation. The localization of endogenous YAP1 was detected by anti-YAP1 antibody in HEK293 cells expressing the indicated SFB-tagged PTPN14 mutants. The localizations of SFB-tagged PTPN14 mutants were detected with anti-Flag antibody. Nuclei were stained by DAPI. (M) Merged.

\section{PTPN14 protein level is elevated}

by increase in cell density

Since the subcellular localization of YAP1 can be controlled by cell density and PTPN14 may act as a tumor suppressor, which could function by inhibiting YAP1 nuclear localization, we asked whether PTPN14 expression would be regulated by cell density.

When MCF10A cells grew from sparse to confluent, the activation of the hippo pathway could increase YAP1 phosphorylation at the Ser 127 site but did not affect the overall YAP1 protein level (Fig. 4A). Contact inhibition led to decreased cell proliferation, which was marked by decreased AKT activation (Fig. 4A). Interestingly, the PTPN14 protein level increased with increases of cell density, while this was not the case for AMOTL2 (Fig. 4A). Similar results were also obtained in other cell lines (Supplemental Fig. S3A). This elevation of PTPN14 protein level was not due to a change in PTPN14 transcriptional level, as PTPN14 mRNA remained the same regardless of the status of cell density (Supplemental Fig. S4A,B). The PTPN14 turnover rate was higher in the sparse cells than that in the confluent cells (Fig. 4B). We immunoprecipitated endogenous PTPN14 and probed for polyubiquitinated PTPN14 in sparse and confluent MCF10A cells. PTPN14 showed more polyubiquitination pattern in cells isolated at low density than those isolated at high density (Fig. 4C). Together these data suggest that PTPN14 protein level is regulated by cell density, which may contribute to cytoplasmic translocation of YAP1 in contact-inhibited cells.

\section{Depletion of PTPN14 inhibits phosphorylation and density-dependent nucleus-to-cytoplasm translocation of YAP1}

We next examined directly whether PTPN14 would promote density-dependent YAP1 translocation in vivo. Knockdown of PTPN14 in MCF10A cells decreased YAP1 phosphorylation but did not affect total YAP1 protein level (Fig. 5A). Reintroduction of shRNA-resistant PTPN14 into PTPN14 knockdown cells reversed YAP1 phosphorylation to a normal level (Fig. 5B). To examine whether density-dependent translocation of YAP1 is affected by the loss of PTPN14, subcellular localization of YAP1 was investigated in confluent PTPN14 knockdown cells. As shown in Figure 5D, YAP1 localized predominantly in the cytoplasm in control shRNA and noneffective PTPN14 shRNA transduced MCF10A cells. However, considerable nuclear localization of YAP1 was detected in PTPN14 knockdown cells expressing two different
A.

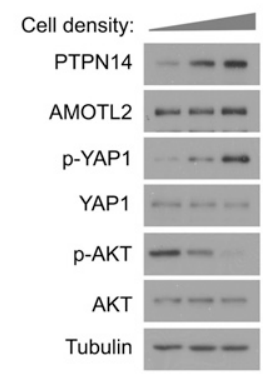

B.

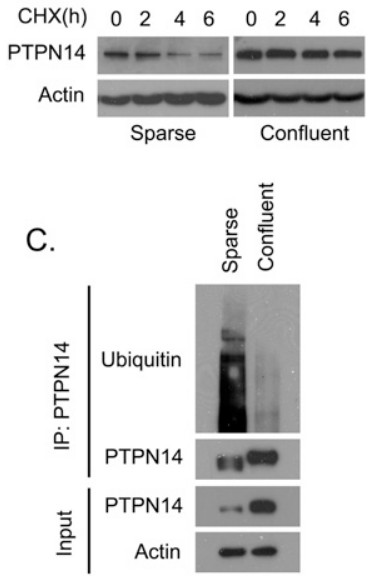

Figure 4. PTPN14 protein stability is regulated by cell density. (A) The expression of PTPN14 increased with cell density. Lysates of $\sim 20 \%$ confluent, $\sim 80 \%$ confluent, and overconfluent MCF10A cells were prepared and analyzed for the indicated total and phosphorylated proteins by Western blotting. $(B)$ The PTPN14 turnover rate was higher in low-density cells. Sparse and confluent MCF10A cells were treated with cycloheximide $(\mathrm{CHX} ; 100 \mu \mathrm{g} / \mathrm{mL})$ for the indicated hours. PTPN14 protein levels were determined by immunoblotting with anti-PTPN14 antiserum. (C) PTPN14 was polyubiquitinated in sparse MCF10A cells. Sparse and confluent MCF10A cells were treated with MG132 $(10 \mu \mathrm{M})$ for $4 \mathrm{~h}$. Cell lysates $(1.5 \mathrm{mg})$ were subjected to immunoprecipitation with purified anti-PTPN14 antibody. Immunoblotting analysis was conducted for the indicated proteins. 


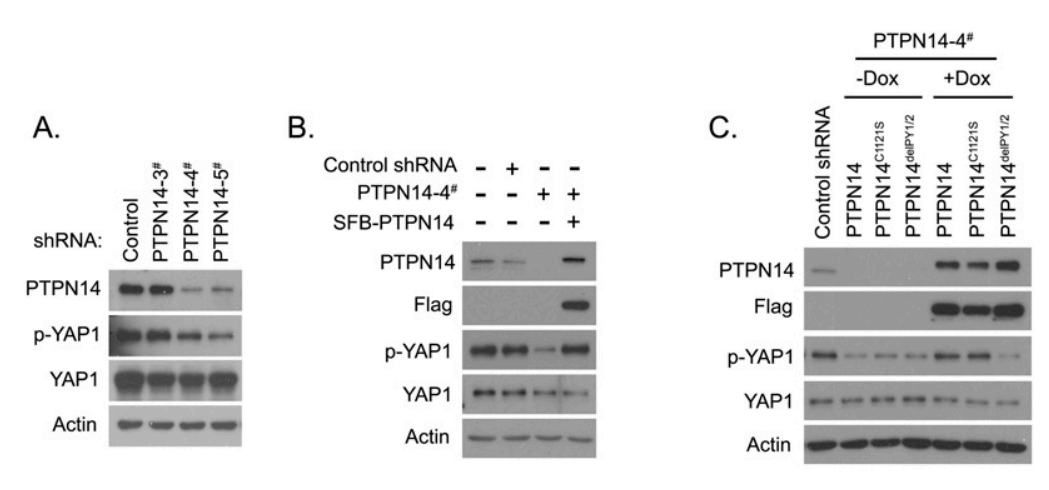

E.

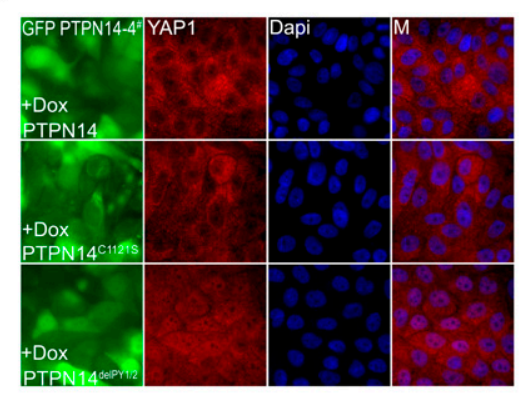

F.

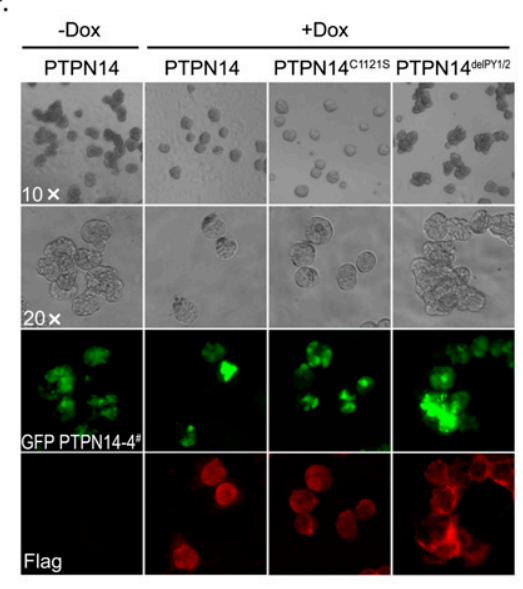

D.

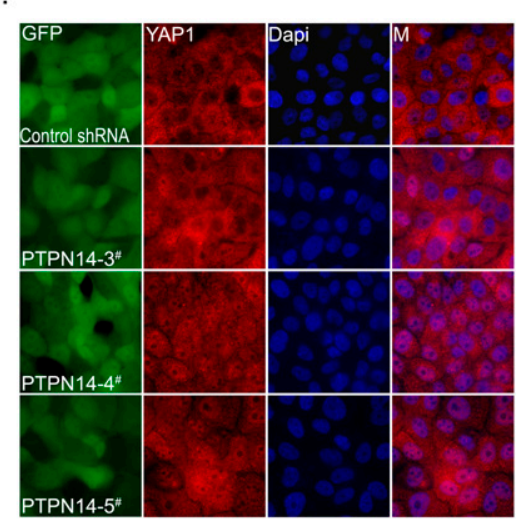

G.

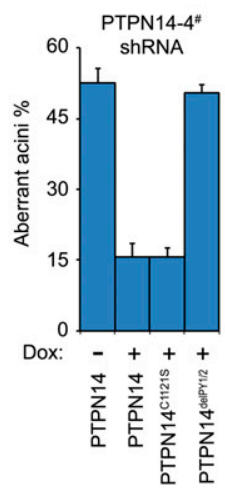

Figure 5. PTPN14 regulates the cell density-dependent nucleus-to-cytoplasm translocation of YAP1. (A) YAP1 phosphorylation decreased in cells with PTPN14 down-regulation. MCF10A cells transfected with PTPN14 shRNAs were analyzed for the indicated total proteins or phosphorylated proteins by Western blotting. (B) YAP1 phosphorylation in PTPN14-depleted MCF10A cells was restored by exogenously expressed PTPN14. RNAi-resistant PTPN14 was transduced into PTPN14-depleted MCF10A cells, and the indicated protein or phosphorylated protein levels were determined by Western blotting. (C) PTPN14 depletion-induced decrease of YAP1 phosphorylation was rescued by the expression of wild-type PTPN14 and its phosphatase-inactive mutant but not the PY motifdeleted mutant of PTPN14. RNAi-resistant inducible PTPN14 and its indicated mutants were transduced into PTPN14-depleted MCF10A cells. The indicated proteins or phosphorylated proteins were analyzed in MCF10A cells cultured with or without doxycycline (Dox) for 24 h. (D) Knockdown of PTPN14 led to defective cell density-dependent translocation of YAP1. Translocation of YAP1 was shown by immunostaining with anti-YAP1 antibody in confluent MCF10A cells expressing the indicated PTPN14 shRNAs. Cells expressing the indicated shRNAs are labeled in green (GFP). Nuclei were stained by DAPI. (M) Merged. (E) Defect in density-dependent YAP1 translocation was rescued by wild-type PTPN14 and its phosphatase-inactive mutant but not by its PY motif-deleted mutant. Translocation of YAP1 was shown by immunostaining with antiYAP1 antibody in confluent PTPN14-depleted MCF10A cells in which expression of RNAi-resistant inducible PTPN14 and its indicated mutants was induced by doxycycline. (F) Aberrant acini morphogenesis in PTPN14-depleted MCF10A cells was rescued by the expression of wild-type PTPN14 or its phosphatase-inactive mutant but not the PY motif-deleted mutant of PTPN14. MCF10A cells expressing RNAi-resistant inducible PTPN14 and its indicated mutants were analyzed for acini formation after culture with or without doxycycline for $8 \mathrm{~d}$. Acinar morphogenesis for the indicated MCF10A cells is shown. The indicated doxycycline-induced proteins were detected by anti-Flag immunostaining. Green (GFP) represents PTPN14-depleted MCF10A cells transduced with shRNAs. $(G)$ Aberrant acini in MCF10A cells expressing RNAi-resistant inducible PTPN14 and its indicated mutants cultured with or without doxycycline were quantified. Data are presented as mean $\pm \mathrm{SD}$ from three different experiments.

shRNAs, which effectively down-regulate PTPN14 expression (Fig. 5D).

To reveal whether the physical interaction between these two proteins is required for the effect of PTPN14 on density-dependent translocation of YAP1, we took advantage of the inducible expression system to express the shRNA-resistant wild-type PTPN14, the phosphatasecatalytic-dead PTPN14 mutant (PTPN14 ${ }^{\mathrm{Cl1} 121 \mathrm{~S}}$ ), and the two PY motif-deleted PTPN14 mutant (PTPN14 $4^{\text {delPY1/2) }}$ in PTPN14-depleted MCF10A cells. As shown in Figure
5C, the expression of wild-type and mutated PTPN14 was induced in PTPN14 knockdown cells when the cells were treated with doxycycline. The decrease of YAP1 phosphorylation was rescued by wild-type PTPN14 and its phosphatase-catalytic-dead mutant, but not by the two PY motif-deleted mutant of PTPN14 (Fig. 5C). Likewise, the defect in YAP1 nucleus-to-cytoplasm translocation was restored by the reintroduction of wild-type PTPN14 or its phosphatase-dead mutant but not the two PY motifdeleted mutant of PTPN14 (Fig. 5E). These results in- 
dicate that physical interaction between PTPN14 and YAP1 is required for the regulation of YAP1 phosphorylation and its density-dependent nucleus-to-cytoplasm translocation. Notably, this regulation is independent of the phosphatase activity of PTPN14.

The interaction between PTPN14 and YAP1 is required for PTPN14 function in suppressing aberrant acini formation in MCF10A cells

To address whether the binding to YAP1 is required for PTPN14 function in acini formation, we reintroduced shRNA-resistant PTPN14, its phosphatase-dead mutant (PTPN14 ${ }^{\mathrm{C} 1121 \mathrm{~S}}$ ), or its two PY motif-deleted mutant (PTPN14 ${ }^{\text {delPY1/2) }}$ in PTPN14-depleted MCF10A cells using a doxycycline-inducible system. Expression of either wild-type PTPN14 or its phosphatase-dead mutant reduced aberrant acini formation caused by the loss of endogenous PTPN14 and restored the normal acini structures (Fig. 5F,G). However, re-expression of the two PY motif-deleted mutant of PTPN14 could not rescue the aberrant acini formation in these cells (Fig. 5F,G). These data confirmed that the direct inhibition of YAP1 by PTPN14 is required for normal acini formation of MCF10A cells, which depends on a physical proteinprotein interaction between PTPN14 and YAP1 but not on PTPN14 phosphatase activity.

\section{The CRL2 ${ }^{L R R 1}$ complex is the E3 ligase involved in PTPN14 degradation}

Since the major regulation of PTPN14 appears to be at its protein stability, we decided to identify the E3 ligase that is responsible for PTPN14 ubiquitination and degradation in sparse cells. We examined the PTPN14-interacting proteins shown in Figure 2A. The mass spectrometry analysis revealed Cul2, which is a subunit of CRL2, as a PTPN14-associated protein. The CRL2 complex is a multisubunit E3 ligase complex that contains several components: (1) the scaffold protein Cullin2; (2) the RING protein Roc1, which recruits the ubiquitin-conjugating enzyme; (3) the adaptor protein Elongin B and Elongin C complex; and (4) a variable substrate-recognizing adaptor protein (Bosu and Kipreos 2008; Hotton and Callis 2008). The substrate-recognizing adaptors determine the specificity as well as the physiological functions of various CRL complexes. Interestingly, besides Cul2, a substraterecognizing adaptor of the CRL2 complex, peptidylprolyl isomerase-like 5 (PPIL-5), was also identified in our mass spectrometry analysis (Fig. 2A). PPIL-5, also called LRR1, was reported to associate with and negatively regulate TNF receptor-associated factor 2-mediated signaling (Jang et al. 2001). The CRL2 ${ }^{\text {LRR } 1}$ E3 ligase complex could also degrade cyclin-dependent kinase inhibitor CKI-1 to promote cell cycle progression in Caenorhabditis elegans germ cells, while in a mammalian system, this E3 complex targeted p21 in the cytoplasm and affected Rho/ROCK/LIMK-mediated actin cytoskeleton remodeling (Starostina et al. 2010). Thus, $\mathrm{CRL}^{\mathrm{LRR} 1}$ is an E3 ligase complex that targets protein for degradation. Here, our mass spectrometry data indicate that CRL2 ${ }^{\mathrm{LRR} 1}$ could be the E3 ligase that targets PTPN14 for degradation.

Indeed, the PTPN14 protein level decreased when LRR1 was overexpressed, and this decrease was reversed by the treatment of proteasome inhibitor MG132 (Fig. 6A). The PTPN14 turnover rate was higher in cells expressing LRR1 than that in control cells (Fig. 6B; Supplemental Fig. S6A). Immunoprecipitation experiments confirmed an interaction between PTPN14 and LRR1 or Cul2 but not between PTPN14 and VHL, a widely studied substraterecognizing adaptor for the CRL2 complex (Fig. 6C). Furthermore, PTPN14 was degraded in a dose-dependent manner by LRR1 but not by VHL (Fig. 6D). The PTPN14 protein level increased in LRR1-depleted MCF10A cells (Fig. 6E), which correlates with reduced PTPN14 polyubiquitination in these cells (Fig. 6F). Collectively, these results suggest that CRL2 ${ }^{\mathrm{LRR} 1}$ is the E3 ligase complex that targets PTPN14 degradation.

The CRL2 ${ }^{L R R 1}$ E3 ligase complex resembles the loss of PTPN14 on YAP1 regulation

Depletion of PTPN14 would inhibit YAP1 phosphorylation and its density-dependent nuclear-to-cytoplasm translocation (Fig. 5). Since CRL2 ${ }^{\mathrm{LRR} 1}$ targets PTPN14 for degradation, we sought to determine whether LRR1 overexpression would affect YAP1 phosphorylation or its density-dependent nucleus-to-cytoplasm translocation. Consistent with our working hypothesis, we found that both the PTPN14 protein level and YAP1 phosphorylation were decreased in MCF10A cells overexpressing LRR1 (Fig. 6G). Accordingly, the PTPN14 polyubiquitination level was higher in MCF10A cells overexpressing LRR1 than that in control cells (Fig. 6H).

We generated a viral-based expression vector that controls the expression of LRR1 and green fluorescent protein (GFP) by separate promoters so that the LRR1expressing cells could be traced by GFP fluorescence. As shown in Figure 6I, YAP1 translocated from the nucleus to the cytoplasm in vector transduced MCF10A cells when cells reached confluence, but YAP1 remained in nuclei in confluent MCF10A cells stably expressing LRR1, a situation similar to that observed in PTPN14depleted cells. These data indicate that CRL2 ${ }^{\text {LRR1 }}$, as the E3 ligase for PTPN14, can inhibit YAP1 phosphorylation and block YAP1 nucleus-to-cytoplasm translocation regulated by cell density.

Since loss of PTPN14 disrupted proper acini formation of MCF10A cells in 3D culture, overexpression of LRR1, which down-regulates PTPN14, should also disrupt the normal acini formation. Indeed, the production of aberrant multiunpolarized acini was dramatically increased in MCF10A cells overexpressing LRR1, while MCF10A cells transfected with control vector showed normal acinar structures (Fig. 6J,K). These data suggest that LRR1 can regulate MCF10A acini morphogenesis at least in part through its ability to suppress PTPN14 expression.

In an attempt to elucidate the density-dependent control of the PTPN14 protein level, we noticed that LRR1 expression was also regulated by cell density. The LRR1 
A.

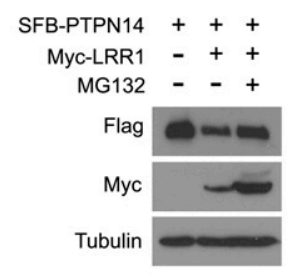

C.

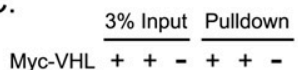

SFB-PTPN14 -++-++

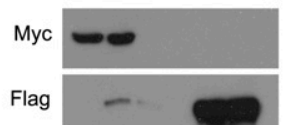

Myc-LRR1 ++-++-

SFB-PTPN14 -++-++
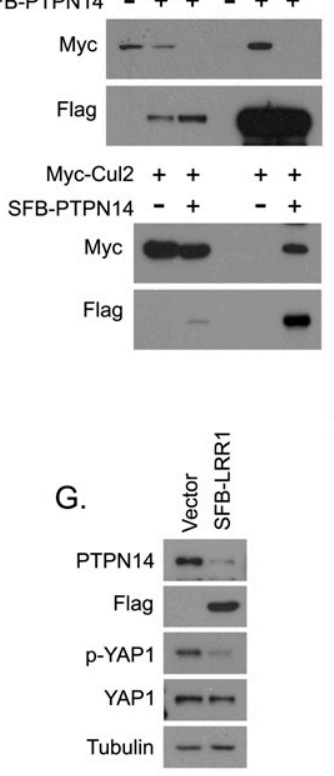

B.

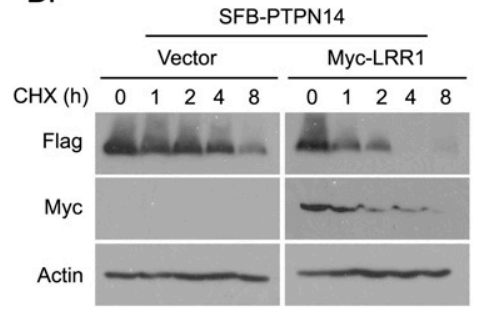

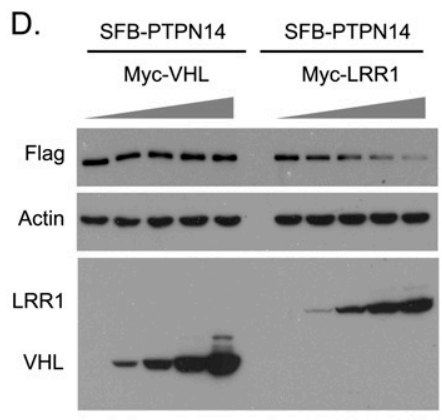

E.

I.
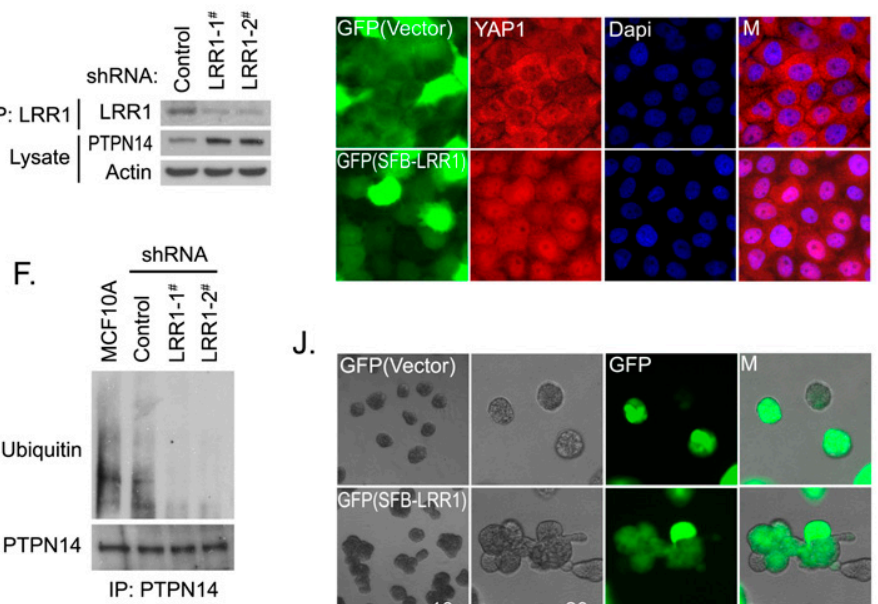

J.

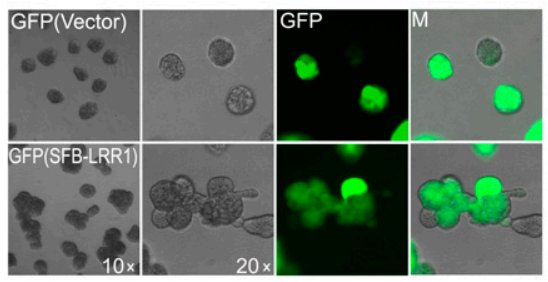

$\mathrm{H}$.

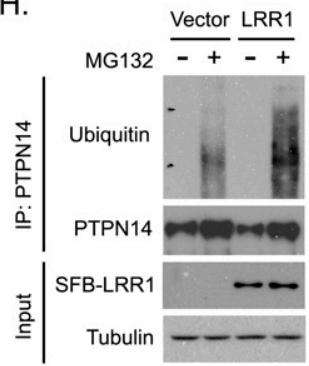

K.

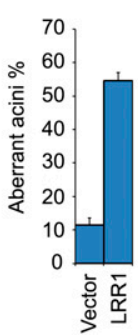

흠
L.

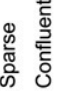

IP: LRR1 | LRR1

\begin{tabular}{l|r} 
Cysate & - \\
PTPN14 - \\
Tubulin -
\end{tabular}

Figure 6. The CRL2 $2^{\mathrm{LRR} 1}$ complex is the E3 ligase that promotes PTPN14 degradation. (A) PTPN14 was degraded by CRL2 ${ }^{\mathrm{LRR} 1}$. Constructs encoding SFB-tagged PTPN14 were transfected into 293T cells with or without constructs encoding myc-tagged LRR1. The indicated cells were treated with MG132 $(10 \mu \mathrm{M})$ for $4 \mathrm{~h}$. Immunoblotting analysis of the indicated proteins is shown. (B) The PTPN14 turnover rate was increased by LRR1 expression. 293T cells expressing PTPN14 with or without LRR1 were treated with cycloheximide $(\mathrm{CHX} ; 100 \mu \mathrm{g} / \mathrm{mL})$ for the indicated hours. Immunoblotting analysis of the indicated proteins is shown. (C) PTPN14 interacts with the CRL2 ${ }^{\mathrm{LRR} 1}$ complex. $293 \mathrm{~T}$ cells were transfected with constructs encoding SFB-tagged PTPN14 along with constructs encoding myc-tagged VHL, LRR1, or Cul2. Precipitation was carried out using S-protein beads, and immunoblotting was performed with antibodies recognizing the indicated epitope tags. $(D)$ CRL2 ${ }^{\text {LRR1 }}$ targets PTPN14 for degradation. PTPN14 was expressed in 293T cells with an increased amount of VHL or LRR1. Immunoblotting analysis of the indicated proteins is shown. (E) PTPN14 expression level was increased by LRR1 knockdown. PTPN14 protein level was detected in MCF10A cells expressing the indicated shRNAs. (F) PTPN14 polyubiquitination decreased in LRR1-depleted MCF10A cells. The indicated shRNA-transduced MCF10A cells were pretreated with MG132 (10 $\mu \mathrm{M})$ for $4 \mathrm{~h}$. Immunoprecipitation was carried out using purified anti-PTPN14 antibody, and immunoblotting was performed with the indicated antibodies. $(G)$ PTPN14 expression was decreased by the overexpression of LRR1 in MCF10A cells. Immunoblotting analysis is shown for the indicated proteins in control cells or MCF10A cells expressing LRR1. (H) PTPN14 polyubiquitination was increased by LRR1 overexpression. Control or MCF10A cells overexpressing LRR1 were cultured with or without MG132 (10 $\mu \mathrm{M})$ for $4 \mathrm{~h}$. Immunoprecipitation was carried out using purified anti-PTPN14 antibody, and immunoblotting was performed with the indicated antibodies. (I) YAP1 translocation was inhibited by LRR1 overexpression in confluent cells. Translocation of YAP1 was shown by immunostaining with anti-YAP1 antibody in confluent MCF10A cells with or without LRR1 overexpression. LRR1-positive cells are indicated by GFP expression (green). Nuclei were stained by DAPI. (M) Merged. (J) Normal polarized acini formation was disrupted by LRR1 overexpression. MCF10A cells with or without LRR1 overexpression were analyzed for acini formation in 3D culture. LRR1-positive cells are indicated by GFP expression (green). (K) Aberrant acini in MCF10A cells expressing vector or LRR1 were quantified. Data are presented as mean \pm SD from three different experiments. $(L)$ The LRR1 protein level was controlled by cell density. Immunoblotting analysis of the indicated proteins in sparse and confluent MCF10As is shown. 
protein level decreased in cells at high density, where PTPN14 tended to be more stable (Fig. 6L). Indeed, we showed that when cells reached confluence, the association of PTPN14 with the CRL2 ${ }^{\text {LRR1 }}$ E3 complex was decreased (Supplemental Fig. S6B), while the Cul2 protein level only decreased slightly in confluent cells (Fig. 6L). These data indicate that the density-dependent regulation of PTPN14 expression may be mainly controlled by the change of the substrate-recognizing adaptor LRR1 of the CRL2 complex.

\section{Discussion}

In this study, we identified nonreceptor tyrosine phosphatase PTPN14 as a negative regulator of cell proliferation and transformation. PTPN14 suppresses the proliferation and transformation of mammary epithelial cells by interfering with the oncoprotein YAP1, a downstream target of the hippo pathway. PTPN14 overexpression leads to the translocation of YAP1 from the nucleus to the cytoplasm, which inhibits its transcriptional activity (Supplemental Fig. S5). PTPN14 is normally expressed at a low level in sparse cells, due to its targeted degradation by the CRL2 ${ }^{\text {LRR1 }}$ E3 ligase complex. However, in confluent cells, PTPN14 is stabilized, in part due to a decrease of LRR1 expression. It binds directly to YAP1, results in YAP1 cytoplasmic localization, and thus inhibits YAP1 transactivation activity in confluent cells.

PTPN14 depletion leads to the transformation of normal mammary epithelial cells and the formation of aberrant acini, which suggests that the loss of PTPN14 expression may promote breast cancer initiation and progression. Loss of PTPN14 increased anchorage-independent growth of MCF10A cells as well as other normal cell lines (Supplemental Fig. S8B-D). Notably, this potential tumor-suppressive function of PTPN14 was not totally dependent on its phosphatase activity. Overexpression of wild-type PTPN14 but not the two PY motifdeleted mutant (PTPN14 ${ }^{\text {delPY1/2 }}$ ) inhibited the anchorageindependent growth of breast cancer cells (Supplemental Fig. S8E,F) and tumor formation in vivo (Supplemental Fig. S8G,H). The phosphatase activity of PTPN14 was hardly detected by in vitro phosphatase assay (Zhu et al. 2008). While we could not exclude the possibility that PTPN14 may dephosphorylate some specific substrates in vivo, based on our studies, we speculate that one of the potential tumor suppressor functions of PTPN14 is to suppress YAP1 activity. During the revision of our manuscript, we noticed two very recent studies on the regulation of YAP1 by PTPN14 (Huang et al. 2012; Liu et al. 2012) that further support our findings presented here.

YAP1 is the downstream target in the hippo signaling pathway, which is critically important for the regulation of cell and tissue growth. YAP1 was identified as an oncogene that promotes cell proliferation, oncogenic transformation, and epithelial-mesenchymal transition through its transcriptional coactivator function (Overholtzer et al. 2006). Overexpression of YAP1 leads to loss of contact inhibition and increases the organ size (Huang et al. 2005;
Camargo et al. 2007). Dysregulation of YAP1 has been identified in various types of cancer (Yuan et al. 2008; Liu et al. 2010; Wu et al. 2010; Orr et al. 2011; Zhang et al. 2011; Diep et al. 2012). Because of its crucial function in tissue growth and tumor development, YAP1 and its regulation have been studied extensively. In mammalian systems, the classic hippo pathway transduces signal from several membrane receptors to the mediator proteins, and finally converges on activation of the MST-LATS kinase cascade. Activated LATS kinase phosphorylates YAP1 and sequesters it in the cytoplasm through 14-3-3 binding. The proteins that regulate YAP1 through the hippo pathway can be grouped into the hippo pathwaydependent regulators such as ASPP1 (Vigneron et al. 2010), NPHP4 (Habbig et al. 2011), and even cytoskeletons (Sansores-Garcia et al. 2011; Wada et al. 2011; Zhao et al. 2012). Some other proteins, such as angiomotin family proteins AMOT, AMOTL1, and AMOTL2, are able to bind directly to YAP1 through PY motif-WW domain-mediated protein interactions. As a note, the angiomotin family proteins were found recently to regulate upstream factors in the hippo pathway (Paramasivam et al. 2011), further complicating our understanding of YAP1 regulation. These proteins can drive YAP1 out of the nucleus independent of the classic phosphorylation-dependent regulation of YAP1. However, it remains a puzzle how these nonclassic hippo pathway regulators sense physiological cues, such as contact inhibition, to control the subcellular localization of YAP1.

In this study, we found that the expression level of PTPN14 is regulated by cell density, which correlates with the density-dependent nucleus-to-cytoplasm translocation of YAP1. This is a specific characteristic of PTPN14, since the expression level of AMOTL2, which is another a key regulator of YAP1 (Wang et al. 2011; Zhao et al. 2011), does not change in a density-dependent manner. These observations suggest that PTPN14 might regulate YAP1 in response to change in cell density, which is distinctly different from that of AMOTL2-dependent regulation of YAP1.

The low expression level of PTPN14 in sparse (lowdensity) cells was due to ubiquitin-proteasome-mediated protein degradation. We identified the CRL2 ${ }^{\text {LRR1 }}$ complex as the E3 ligase that targets PTPN14 for degradation. Overexpression of the substrate-recognizing adaptor LRR1 in MCF10A cells not only degrades PTPN14, but also blocks the density-dependent nucleus-to-cytoplasm translocation of YAP1 and leads to the aberrant acini formation of MCF10A cells in 3D culture. Interestingly, the expression level of LRR1 also decreases when cells reach confluence, which makes the association of PTPN14 with the CRL2 ${ }^{\mathrm{LRR} 1}$ E3 complex decrease. These observations not only functionally confirmed CRL2 $2^{\mathrm{LRR} 1}$ as the E3 ligase for PTPN14, but more importantly present a new

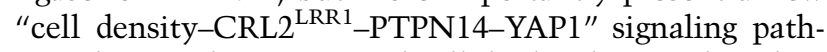
way that regulates YAP1 subcellular localization based on the change in cell density. We still do not know the precise mechanism of how cell density regulates the LRR1-mediated PTPN14 degradation. One possible explanation is 
that LRR1 is also targeted for degradation when cells grow confluent, as the LRR1 protein level increased after MG132 treatment (Fig. 6A). However, this still does not provide the critical link between contact inhibition and LRR1/PTPN14 degradation.

It is conceivable that different regulators of YAP1 may control its activity in tissue-specific and/or signal-specific manners. For example, although all three AMOT proteins (AMOT, AMOTL1, and AMOTL2) can bind to and regulate YAP1, the expression of AMOT is very restricted and was only detected in 293T cells (Zhao et al. 2011). AMOTL2 seems to be the major regulator of certain functions of YAP1, since only knockdown of AMOTL2, but not that of AMOTL1 or PTPN14, could induce the epithelial-to-mesenchymal transition via YAP1 activation in MCF10A cells (Wang et al. 2011). On the other hand, the density-dependent translocation of YAP1 is regulated by PTPN14, since only the stability of PTPN14, but not that of AMOTL2, is controlled by cell density. These observations suggest the existence of an extensive network composed of a series of negative regulators, besides the classic hippo signaling pathway, that control the physiological functions of YAP1.

We could not detect any association of PTPN14 with angiomotin family proteins (Supplemental Fig. S7A,B). Knockdown of both PTPN14 and AMOTL2 can further activate YAP1 and increase cell proliferation (Supplemental Fig. S7C,E-G). These data suggest that PTPN14 regulates YAP1 independent of angiomotin family proteins. How these regulators coordinate with the hippo pathway to control YAP1 remains unclear and deserves further investigation.

\section{Materials and methods}

\section{Antibodies}

Anti-PTPN14 antibody was raised by immunizing a rabbit with a bacterially expressed and purified GST-PTPN14 fusion protein containing the 400 800 amino acids of human PTPN14. AntiYAP1 antibody was raised by immunizing a rabbit with bacterially expressed and purified GST-fused human full-length YAP1 protein. Anti-LRR1 antibody was raised by immunizing a rabbit with bacterially expressed and purified MBP-fused human fulllength LRR1 protein. Antisera were affinity-purified using the AminoLink Plus immobilization and purification kit (Pierce). Anti-YAP1 and phosphor-YAP1 (S127) antibodies were purchased from Santa Cruz Biotechnology and Cell Signaling Technology, respectively. Anti- $\beta$-actin, anti- $\alpha$-tubulin, and anti-Flag (M2) monoclonal antibodies and anti-Flag polyclonal antibody were obtained from Sigma-Aldrich. Anti-myc and anti-GFP monoclonal antibodies were purchased from Santa Cruz Biotechnology. Anti-AKT1 and anti-phoshor-AKT1 (Ser473) polyclonal antibodies were purchased from Cell Signaling Technology. Antiubiquitin monoclonal antibody was obtained from Millipore. Anti-Cul2 polyclonal antibody was purchased from Invitrogen.

\section{Constructs and viruses}

The YAP1 construct was purchased from Open Biosystems. PTPN3, PTPN4, PPIL-5 (LRR1), Cul2, and VHL constructs were obtained from the Human ORFeome version 5.1 collection. Flag- tagged LRR1 was kindly provided by Dr. Natalia G. Starostina (University of Georgia). All constructs were generated by PCR and subcloned into pDONOR201 vector using Gateway Technology (Invitrogen) as the entry clones. As needed, the entry clones were subsequently recombined into gateway-compatible destination vectors for the expression of N-terminal- or C-terminal-tagged fusion proteins. PCR-mediated site-directed mutagenesis was used to generate serial point mutations or deletions. The PTPN14 FERM domain truncation was generated by deleting amino acids 1 340. The PTPN14 linker1 domain deletion was generated by deleting amino acids $341 \sim 500$. The PTPN14 linker2 domain deletion was generated by deleting amino acids 501 800. The PTPN14 linker3 domain deletion was generated by deleting amino acids 801 929. The PTPN14 PTP domain truncation was generated by deleting amino acids $930 \sim 1187$. The PTPN14 first PY motif deletion was generated by deleting amino acids 567 570. The PTPN14 second PY motif deletion was generated by deleting amino acids $749 \sim 752$. The PTPN14 catalytic-dead mutation was generated by replacing Cys1121 with Ser. The YAP1 first WW domain deletion was generated by deleting amino acids $172 \sim 203$. The YAP1 second WW domain deletion was generated by deleting amino acids 232 263 (Wang et al. 2011).

Five individual pGIPZ lentiviral shRNAs targeting PTPN14 were obtained from the shRNA and ORFeome Core Facility at The University of Texas M.D. Anderson Cancer Center. The shRNA sequences were as follows: PTPN14 shRNA-1 ${ }^{\#}$ (V2LHS 70672), 5'-GCCACAAGATATCAGTATT-3'; PTPN14 shRNA-2 ${ }^{\#}$ (V2LHS_70676), 5'-CCCACATGCTTAAGAACTA-3'; PTPN14 shRNA-3" ${ }^{\#}$ (V2LHS_250104), 5' -CCTGGACTTAAATTATTTA-3'; PTPN14 shRNA-4 ${ }^{\#}$ (V2LHS_248245), 5' -CAGAGGAACCCAA AGAATA-3'; PTPN14 shRNA-5 ${ }^{\#}$ (V3LHS_378143), 5' -AAGT TCAAGGTCACCACGA-3'; and control shRNA, 5' -TCTCGC TTGGGCGAGAGTAAG-3'.

The PTPN14 shRNA-4"-resistant expression construct was generated by mutating the nucleotide sequence without changing the translated amino acid sequence. The original shRNA targeting sequence (5'-CAGAGGAACCCAAAGAATA-3') was

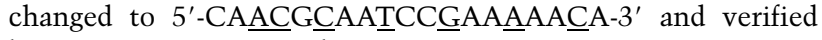
by sequencing. YAP1 shRNA, 5'-CAGGTGATACTATCAAC CAAA-3'; LRR1shRNA-1 ${ }^{\#}$ (V3LHS_339457), 5'-TCCTGTGGA TATCTGTCTA-3'; and LRR1 shRNA-2 (V3LHS_339456), 5' -AA GATTTGGATACCGCAAA- ${ }^{\prime}$.

The SFB-LRR1 lentiviral expression vector was generated by inserting the gateway response fragment (attR1-ccdB-attR2)fused SFB tag into the XbaI and SwaI multiclonal sites of the pCDH-CMV-EF1-GFP vector (kindly provided by Dr. M. James You, M.D. Anderson Cancer Center). LRR1 was cloned into this vector through a gateway-based LR reaction.

All lentiviral supernatants were generated by transient transfection of 293T cells with helper plasmids pSPAX2 and pMD2G (kindly provided by Dr. Zhou Songyang, Baylor College of Medicine) and harvested $48 \mathrm{~h}$ after transfection. Supernatants were passed through a $0.45-\mu \mathrm{m}$ filter and used to infect MCF10A cells with the addition of $8 \mu \mathrm{g} / \mathrm{mL}$ polybrene.

\section{Cell culture and transfection}

HEK293 and 293T cells were purchased from American Type Culture Collection and maintained in Dulbecco's modified essential medium (DMEM) supplemented with $10 \%$ fetal bovine serum at $37^{\circ} \mathrm{C}$ in $5 \% \mathrm{CO}_{2}(\mathrm{v} / \mathrm{v})$. MCF10A cells were kindly provided by Dr. Dihua Yu (M.D. Anderson Cancer Center). MCF10A cells were maintained in DMEM/F12 medium supplemented with $5 \%$ horse serum, $200 \mathrm{ng} / \mathrm{mL}$ epidermal growth factor, $500 \mathrm{ng} / \mathrm{mL}$ hydrocortisone, $100 \mathrm{ng} / \mathrm{mL}$ cholera toxin, and 
$10 \mu \mathrm{g} / \mathrm{mL}$ insulin at $37^{\circ} \mathrm{C}$ in $5 \% \mathrm{CO}_{2}$ (v/v). HMLE cells were kindly provided by Dr. Li Ma (M.D. Anderson Cancer Center) and maintained in mammary epithelial cell growth medium (Lonza Walkersville, Inc.). All culture media contained 1\% penicillin and streptomycin antibiotics. Plasmid transfection was performed using the polyethylenimine reagent.

\section{Tandem affinity purification of SFB-tagged protein complexes}

293 T cells were transfected with plasmids encoding SFB-tagged PTPN14. Cell lines stably expressing the tagged PTPN14 were selected by culturing in medium containing $2 \mu \mathrm{g} / \mathrm{mL}$ puromycin and confirmed by immunostaining and Western blotting. For affinity purification, 293T cells were subjected to lysis in NETN buffer (with protease inhibitors) for $20 \mathrm{~min}$ at $4^{\circ} \mathrm{C}$. Crude lysates were subjected to centrifugation at $14,000 \mathrm{rpm}$ for $15 \mathrm{~min}$ at $4^{\circ} \mathrm{C}$. Supernatants were incubated with streptavidin-conjugated beads (Amersham) for $4 \mathrm{~h}$ at $4^{\circ} \mathrm{C}$. The beads were washed three times with NETN buffer, and bound proteins were eluted with NETN buffer containing $2 \mathrm{mg} / \mathrm{mL}$ biotin (Sigma) overnight at $4^{\circ} \mathrm{C}$. The elutes were incubated with $\mathrm{S}$ protein beads for $4 \mathrm{~h}$ (Novagen). The beads were washed three times with NETN buffer and subjected to sodium dodecyl sulfate polyacrylamide gel electrophoresis (SDS-PAGE). Protein bands were excised and subjected to mass spectrometry analysis (performed by Taplin Mass Spectrometry Facility, Harvard Medical School).

\section{GST pull-down assay}

GST-fused YAP1 was expressed and purified in Escherichia coli BL2 1 cells. GST-YAP1 protein $(2 \mu \mathrm{g})$ was immobilized on glutathione-sepharose 4B beads and incubated with various cell lysates for $2 \mathrm{~h}$ at $4^{\circ} \mathrm{C}$. Beads were washed three times. Proteins bound to beads were eluted and subjected to SDS-PAGE and Western blotting analysis.

\section{Immunofluorescent staining}

Immunofluorescent staining was performed as described previously (Wang et al. 2008). Briefly, cells cultured on coverslips were fixed by $4 \%$ paraformaldehyde for $10 \mathrm{~min}$ at room temperature and then extracted with $0.5 \%$ Triton X-100 solution for $5 \mathrm{~min}$. After blocking with phosphate-buffered saline solution (PBS) containing $1 \%$ bovine serum albumin, cells were incubated with indicated primary antibodies for $1 \mathrm{~h}$ at room temperature. After that, cells were washed and incubated with fluorescein isothiocyanate (FITC), rhodamine-conjugated second primary antibodies, or tetramethyl rhodamine isothiocyanate (TRITC)-conjugated phalloidin for $1 \mathrm{~h}$. Cells were counterstained with $100 \mathrm{ng} / \mathrm{mL}$ DAPI for $2 \mathrm{~min}$ to visualize nuclear DNA. The coverslips were mounted onto glass slides with anti-fade solution and visualized under a Nikon ECLIPSE E800 fluorescence microscope with a Nikon Plan Fluor $60 \times$ oil objective lens (NA 1.30).

\section{Anchorage-independent growth on soft agar}

Infected MCF10A cells $\left(2 \times 10^{4}\right)$ were added to $1.5 \mathrm{~mL}$ of growth medium with $0.33 \%$ agar and layered onto beds of $0.5 \%$ agar $(2$ $\mathrm{mL}$ ) in six-well plates. Cells were fed with $1 \mathrm{~mL}$ of medium with $0.33 \%$ agar every $7 \mathrm{~d}$ for $4 \mathrm{wk}$, after which colonies were stained with $0.02 \%$ crystal violet (Fisher Scientific) and photographed. Colonies $>50 \mu \mathrm{m}$ in diameter were counted as positive for growth. Assays were conducted in duplicate in three independent experiments.

\section{D culture of MCF10A cells for acini formation}

MCF10A cells $\left(5 \times 10^{3}\right)$ stably transfected or infected with control shRNA, PTPN14 shRNAs, or constructs encoding doxycycline-inducible PTPN14 protein and constitutive LRR1 protein were grown in growth factor-reduced BD Matrigel matrix (BD Biosciences) within the eight-well chamber slide system (Fisher Scientific). Cultured cells were analyzed for aberrant acini after $8 \mathrm{~d}$ of growth in Matrigel, and at least three replicates ( $\sim 150$ GFP-positive acini counted per replicate) were performed. To visualize Ki67 localization or SFB-PTPN14 expression, acini were stained with anti-Ki67 or Flag antibody as described (Debnath et al. 2003). Doxycycline ( $400 \mathrm{ng} / \mathrm{mL}$ ) was added to the medium and refreshed every $2 \mathrm{~d}$ to maintain the expression of PTPN14 and its indicated mutants.

\section{Acknowledgments}

We thank all colleagues in J.C.'s laboratory for insightful discussion and technical assistance, especially Dr. Justin Wai Chung Leung. We thank Dr. Gargi Ghosal for the critical reading of the manuscript. We thank Dr. Yutong Sun and the shRNAORFeome Core Facility at M.D. Anderson Cancer Center for the PTP shRNA library. We thank Dr. Jinsong Zhang, Dr. Peijing Zhang, Dr. HaeYun Jung, and Dr. Han-Cheon Kim for technical assistance. This work was supported in part by the Department of Defense (DOD) Era of Hope research scholar award to J.C. (W81XWH-09-1-0409). J.C. is also a recipient of an Era of Hope Scholar award from the Department of Defense (W81XWH-051-0470) and a member of the M.D. Anderson Cancer Center (CA016672).

\section{References}

Alonso A, Sasin J, Bottini N, Friedberg I, Friedberg I, Osterman A, Godzik A, Hunter T, Dixon J, Mustelin T. 2004. Protein tyrosine phosphatases in the human genome. Cell 117: 699711.

Ardini E, Agresti R, Tagliabue E, Greco M, Aiello P, Yang LT, Menard S, Sap J. 2000. Expression of protein tyrosine phosphatase $\alpha(\mathrm{RPTP} \alpha)$ in human breast cancer correlates with low tumor grade, and inhibits tumor cell growth in vitro and in vivo. Oncogene 19: 4979-4987.

Au AC, Hernandez PA, Lieber E, Nadroo AM, Shen YM, Kelley KA, Gelb BD, Diaz GA. 2010. Protein tyrosine phosphatase PTPN14 is a regulator of lymphatic function and choanal development in humans. Am J Hum Genet 87: 436-444.

Barr AJ, Debreczeni JE, Eswaran J, Knapp S. 2006. Crystal structure of human protein tyrosine phosphatase 14 (PTPN14) at $1.65-\AA$ resolution. Proteins 63: 1132-1136.

Benzinou M, Clermont FF, Letteboer TG, Kim JH, Espejel S, Harradine KA, Arbelaez J, Luu MT, Roy R, Quigley D, et al. 2012. Mouse and human strategies identify PTPN14 as a modifier of angiogenesis and hereditary haemorrhagic telangiectasia. Nat Commun 3: 616. doi: 10.1038/ncomms1633.

Bissell MJ, Radisky DC, Rizki A, Weaver VM, Petersen OW. 2002. The organizing principle: Microenvironmental influences in the normal and malignant breast. Differentiation 70: $537-546$.

Bosu DR, Kipreos ET. 2008. Cullin-RING ubiquitin ligases: Global regulation and activation cycles. Cell Div 3: 7. doi: 10.1186/1747-1028-3-7.

Camargo FD, Gokhale S, Johnnidis JB, Fu D, Bell GW, Jaenisch R, Brummelkamp TR. 2007. YAP1 increases organ size and expands undifferentiated progenitor cells. Curr Biol 17: 2054-2060. 
Chan DW, Liu VW, Tsao GS, Yao KM, Furukawa T, Chan KK, Ngan HY. 2008. Loss of MKP3 mediated by oxidative stress enhances tumorigenicity and chemoresistance of ovarian cancer cells. Carcinogenesis 29: 1742-1750.

Chan SW, Lim CI, Chong YF, Pobbati AV, Huang C, Hong W. 2011. Hippo pathway-independent restriction of TAZ and YAP by angiomotin. J Biol Chem 286: 7018-7026.

Da CL, Xin Y, Zhao J, Luo XD. 2009. Significance and relationship between Yes-associated protein and survivin expression in gastric carcinoma and precancerous lesions. World J Gastroenterol 15: 4055-4061.

Debnath J, Muthuswamy SK, Brugge JS. 2003. Morphogenesis and oncogenesis of MCF-10A mammary epithelial acini grown in three-dimensional basement membrane cultures. Methods 30: 256-268.

Denkert C, Schmitt WD, Berger S, Reles A, Pest S, Siegert A, Lichtenegger W, Dietel M, Hauptmann S. 2002. Expression of mitogen-activated protein kinase phosphatase-1 (MKP-1) in primary human ovarian carcinoma. Int I Cancer 102: 507513.

Diep CH, Zucker KM, Hostetter G, Watanabe A, Hu C, Munoz RM, Von Hoff DD, Han H. 2012. Down-regulation of Yes associated protein 1 expression reduces cell proliferation and clonogenicity of pancreatic cancer cells. PLOS ONE 7: e32783. doi: 10.1371/journal.pone.0032783.

Fridberg M, Kjellstrom S, Anagnostaki L, Skogvall I, Mustelin T, Wiebe T, Persson JL, Dictor M, Wingren AG. 2008. Immunohistochemical analyses of phosphatases in childhood B-cell lymphoma: Lower expression of PTEN and HePTP and higher number of positive cells for nuclear SHP2 in B-cell lymphoma cases compared to controls. Pediatr Hematol Oncol 25: 528-540.

Garcia JM, Silva J, Pena C, Garcia V, Rodriguez R, Cruz MA, Cantos B, Provencio M, Espana P, Bonilla F. 2004. Promoter methylation of the PTEN gene is a common molecular change in breast cancer. Genes Chromosomes Cancer 41: 117-124.

Habbig S, Bartram MP, Muller RU, Schwarz R, Andriopoulos N, Chen S, Sagmuller JG, Hoehne M, Burst V, Liebau MC, et al. 2011. NPHP4, a cilia-associated protein, negatively regulates the Hippo pathway. I Cell Biol 193: 633-642.

Hanahan D, Weinberg RA. 2011. Hallmarks of cancer: The next generation. Cell 144: 646-674.

Hellberg CB, Burden-Gulley SM, Pietz GE, Brady-Kalnay SM. 2002. Expression of the receptor protein-tyrosine phosphatase, PTPmu, restores E-cadherin-dependent adhesion in human prostate carcinoma cells. J Biol Chem 277: 11165-11173.

Hotton SK, Callis J. 2008. Regulation of cullin RING ligases. Annu Rev Plant Biol 59: 467-489.

Huang J, Wu S, Barrera J, Matthews K, Pan D. 2005. The Hippo signaling pathway coordinately regulates cell proliferation and apoptosis by inactivating Yorkie, the Drosophila homo$\log$ of YAP. Cell 122: 421-434.

Huang JM, Nagatomo I, Suzuki E, Mizuno T, Kumagai T, Berezov A, Zhang H, Karlan B, Greene MI, Wang Q. 2012. YAP modifies cancer cell sensitivity to EGFR and survivin inhibitors and is negatively regulated by the non-receptor type protein tyrosine phosphatase 14. Oncogene doi: 10.1038/ onc.2012.231

Jang LK, Lee ZH, Kim HH, Hill JM, Kim JD, Kwon BS. 2001. A novel leucine-rich repeat protein (LRR-1): Potential involvement in 4-1BB-mediated signal transduction. Mol Cells 12: $304-312$.

Julien SG, Dube N, Hardy S, Tremblay ML. 2011. Inside the human cancer tyrosine phosphatome. Nat Rev Cancer 11: $35-49$.
Laczmanska I, Sasiadek MM. 2011. Tyrosine phosphatases as a superfamily of tumor suppressors in colorectal cancer. Acta Biochim Pol 58: 467-470.

Lemmon MA, Schlessinger J. 2010. Cell signaling by receptor tyrosine kinases. Cell 141: 1117-1134.

Levea CM, McGary CT, Symons JR, Mooney RA. 2000. PTP LAR expression compared to prognostic indices in metastatic and non-metastatic breast cancer. Breast Cancer Res Treat 64: 221-228.

Liaw D, Marsh DJ, Li J, Dahia PL, Wang SI, Zheng Z, Bose S, Call KM, Tsou HC, Peacocke M, et al. 1997. Germline mutations of the PTEN gene in Cowden disease, an inherited breast and thyroid cancer syndrome. Nat Genet 16: 64-67.

Liu AM, Xu MZ, Chen J, Poon RT, Luk JM. 2010. Targeting YAP and Hippo signaling pathway in liver cancer. Expert Opin Ther Targets 14: 855-868.

Liu X, Yang N, Figel SA, Wilson KE, Morrison CD, Gelman IH, Zhang J. 2012. PTPN14 interacts with and negatively regulates the oncogenic function of YAP. Oncogene doi: 10.1038/ onc.2012.147.

Nakamura $M$, Kishi $M$, Sakaki T, Hashimoto $H$, Nakase $H$, Shimada K, Ishida E, Konishi N. 2003. Novel tumor suppressor loci on 6q22-23 in primary central nervous system lymphomas. Cancer Res 63: 737-741.

Ogata M, Takada T, Mori Y, Oh-hora M, Uchida Y, Kosugi A, Miyake K, Hamaoka T. 1999. Effects of overexpression of PTP36, a putative protein tyrosine phosphatase, on cell adhesion, cell growth, and cytoskeletons in HeLa cells. J Biol Chem 274: 12905-12909.

Oka T, Schmitt AP, Sudol M. 2012. Opposing roles of angiomotin-like-1 and zona occludens-2 on pro-apoptotic function of YAP. Oncogene 31: 128-134.

Orr BA, Bai H, Odia Y, Jain D, Anders RA, Eberhart CG. 2011. Yes-associated protein 1 is widely expressed in human brain tumors and promotes glioblastoma growth. I Neuropathol Exp Neurol 70: 568-577.

Overholtzer M, Zhang J, Smolen GA, Muir B, Li W, Sgroi DC, Deng CX, Brugge JS, Haber DA. 2006. Transforming properties of YAP, a candidate oncogene on the chromosome 11q22 amplicon. Proc Natl Acad Sci 103: 12405-12410.

Pan D. 2007. Hippo signaling in organ size control. Genes Dev 21: $886-897$

Paramasivam M, Sarkeshik A, Yates JR III, Fernandes MJ, McCollum D. 2011. Angiomotin family proteins are novel activators of the LATS2 kinase tumor suppressor. Mol Biol Cell 22: 3725-3733.

Sallee JL, Wittchen ES, Burridge K. 2006. Regulation of cell adhesion by protein-tyrosine phosphatases: II. Cell-cell adhesion. J Biol Chem 281: 16189-16192.

Sansores-Garcia L, Bossuyt W, Wada K, Yonemura S, Tao C, Sasaki H, Halder G. 2011. Modulating F-actin organization induces organ growth by affecting the Hippo pathway. EMBO J 30: 2325-2335.

Smith AL, Mitchell PJ, Shipley J, Gusterson BA, Rogers MV, Crompton MR. 1995. Pez: A novel human cDNA encoding protein tyrosine phosphatase- and ezrin-like domains. Biochem Biophys Res Commun 209: 959-965.

Starostina NG, Simpliciano JM, McGuirk MA, Kipreos ET. 2010. CRL2(LRR-1) targets a CDK inhibitor for cell cycle control in C. elegans and actin-based motility regulation in human cells. Dev Cell 19: 753-764.

Sudol M, Bork P, Einbond A, Kastury K, Druck T, Negrini M, Huebner K, Lehman D. 1995. Characterization of the mammalian YAP (Yes-associated protein) gene and its role in defining a novel protein module, the WW domain. I Biol Chem 270: 14733-14741. 
Sun T, Aceto N, Meerbrey KL, Kessler JD, Zhou C, Migliaccio I, Nguyen DX, Pavlova NN, Botero M, Huang J, et al. 2011. Activation of multiple proto-oncogenic tyrosine kinases in breast cancer via loss of the PTPN12 phosphatase. Cell 144: 703-718.

Tonks NK. 2006. Protein tyrosine phosphatases: From genes, to function, to disease. Natl Rev 7: 833-846.

Vigneron AM, Ludwig RL, Vousden KH. 2010. Cytoplasmic ASPP1 inhibits apoptosis through the control of YAP. Genes Dev 24: 2430-2439.

Wada K, Itoga K, Okano T, Yonemura S, Sasaki H. 2011. Hippo pathway regulation by cell morphology and stress fibers. Development 138: 3907-3914.

Wadham C, Gamble JR, Vadas MA, Khew-Goodall Y. 2000. Translocation of protein tyrosine phosphatase Pez/PTPD2/ PTP36 to the nucleus is associated with induction of cell proliferation. J Cell Sci 113: 3117-3123.

Wadham C, Gamble JR, Vadas MA, Khew-Goodall Y. 2003. The protein tyrosine phosphatase Pez is a major phosphatase of adherens junctions and dephosphorylates $\beta$-catenin. Mol Biol Cell 14: 2520-2529.

Wang Z, Shen D, Parsons DW, Bardelli A, Sager J, Szabo S, Ptak J, Silliman N, Peters BA, van der Heijden MS, et al. 2004. Mutational analysis of the tyrosine phosphatome in colorectal cancers. Science 304: 1164-1166.

Wang W, Chen L, Ding Y, Jin J, Liao K. 2008. Centrosome separation driven by actin-microfilaments during mitosis is mediated by centrosome-associated tyrosine-phosphorylated cortactin. J Cell Sci 121: 1334-1343.

Wang W, Huang J, Chen J. 2011. Angiomotin-like proteins associate with and negatively regulate YAP1. I Biol Chem 286: 4364-4370.

Webb C, Upadhyay A, Giuntini F, Eggleston I, Furutani-Seiki M, Ishima R, Bagby S. 2011. Structural features and ligand binding properties of tandem WW domains from YAP and TAZ, nuclear effectors of the Hippo pathway. Biochemistry 50: 3300-3309.

Wu C, Xu B, Yuan P, Miao X, Liu Y, Guan Y, Yu D, Xu J, Zhang $\mathrm{T}$, Shen $\mathrm{H}$, et al. 2010. Genome-wide interrogation identifies YAP1 variants associated with survival of small-cell lung cancer patients. Cancer Res 70: 9721-9729.

Wyatt L, Khew-Goodall Y. 2008. PTP-Pez: A novel regulator of TGF $\beta$ signaling. Cell Cycle 7: 2290-2295.

Wyatt L, Wadham C, Crocker LA, Lardelli M, Khew-Goodall Y. 2007. The protein tyrosine phosphatase Pez regulates TGF $\beta$, epithelial-mesenchymal transition, and organ development. J Cell Biol 178: 1223-1235.

Yagi R, Chen LF, Shigesada K, Murakami Y, Ito Y. 1999. A WW domain-containing yes-associated protein (YAP) is a novel transcriptional co-activator. EMBO J 18: 2551-2562.

Ying J, Li H, Cui Y, Wong AH, Langford C, Tao Q. 2006. Epigenetic disruption of two proapoptotic genes MAPK10/ JNK3 and PTPN13/FAP-1 in multiple lymphomas and carcinomas through hypermethylation of a common bidirectional promoter. Leukemia 20: 1173-1175.

Yuan M, Tomlinson V, Lara R, Holliday D, Chelala C, Harada T, Gangeswaran R, Manson-Bishop C, Smith P, Danovi SA, et al. 2008. Yes-associated protein (YAP) functions as a tumor suppressor in breast. Cell Death Differ 15: 1752-1759.

Zender L, Spector MS, Xue W, Flemming P, Cordon-Cardo C, Silke J, Fan ST, Luk JM, Wigler M, Hannon GJ, et al. 2006. Identification and validation of oncogenes in liver cancer using an integrative oncogenomic approach. Cell 125: 1253-1267.

Zeng Q, Hong W. 2008. The emerging role of the hippo pathway in cell contact inhibition, organ size control, and cancer development in mammals. Cancer Cell 13: 188-192.
Zhang J, Ji JY, Yu M, Overholtzer M, Smolen GA, Wang R, Brugge JS, Dyson NJ, Haber DA. 2009. YAP-dependent induction of amphiregulin identifies a non-cell-autonomous component of the Hippo pathway. Nat Cell Biol 11: 14441450.

Zhang L, Ye DX, Pan HY, Wei KJ, Wang LZ, Wang XD, Shen GF, Zhang ZY. 2011. Yes-associated protein promotes cell proliferation by activating Fos related activator-1 in oral squamous cell carcinoma. Oral Oncol 47: 693-697.

Zhao B, Wei X, Li W, Udan RS, Yang Q, Kim J, Xie J, Ikenoue T, $\mathrm{Yu}$ J, Li L, et al. 2007. Inactivation of YAP oncoprotein by the Hippo pathway is involved in cell contact inhibition and tissue growth control. Genes Dev 21: 2747-2761.

Zhao B, Lei QY, Guan KL. 2008a. The Hippo-YAP pathway: New connections between regulation of organ size and cancer. Curr Opin Cell Biol 20: 638-646.

Zhao B, Ye X, Yu J, Li L, Li W, Li S, Yu J, Lin JD, Wang CY, Chinnaiyan AM, et al. 2008b. TEAD mediates YAP-dependent gene induction and growth control. Genes Dev 22: 1962-1971.

Zhao B, Li L, Lu Q, Wang LH, Liu CY, Lei Q, Guan KL. 2011. Angiomotin is a novel Hippo pathway component that inhibits YAP oncoprotein. Genes Dev 25: 51-63.

Zhao B, Li L, Wang L, Wang CY, Yu J, Guan KL. 2012. Cell detachment activates the Hippo pathway via cytoskeleton reorganization to induce anoikis. Genes Dev 26: 54-68.

Zheng J, Kulp SK, Zhang Y, Sugimoto Y, Dayton MA, Govindan MV, Brueggemeier RW, Lin YC. 2000. $17 \beta$-estradiol-regulated expression of protein tyrosine phosphatase $\gamma$ gene in cultured human normal breast and breast cancer cells. Anticancer Res 20: 11-19.

Zhu JH, Chen R, Yi W, Cantin GT, Fearns C, Yang Y, Yates JR III, Lee JD. 2008. Protein tyrosine phosphatase PTPN13 negatively regulates Her2/ErbB2 malignant signaling. Oncogene 27: 2525-2531. 


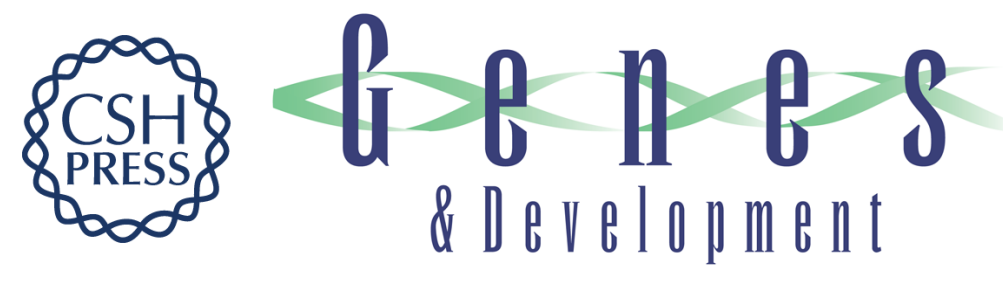

\section{PTPN14 is required for the density-dependent control of YAP1}

Wenqi Wang, Jun Huang, Xin Wang, et al.

Genes Dev. 2012, 26:

Access the most recent version at doi:10.1101/gad.192955.112

Supplemental http://genesdev.cshlp.org/content/suppl/2012/08/28/26.17.1959.DC1
Material

References This article cites 67 articles, 24 of which can be accessed free at: http://genesdev.cshlp.org/content/26/17/1959.full.html\#ref-list-1

License

Email Alerting Receive free email alerts when new articles cite this article - sign up in the box at the top Service right corner of the article or click here.

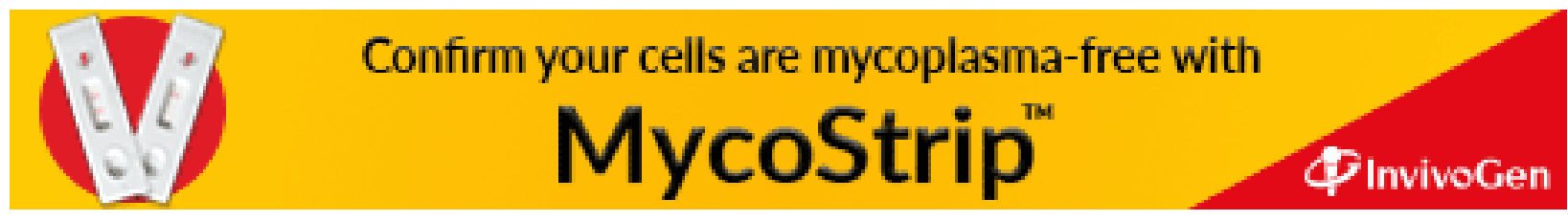

